\title{
Differential Diagnosis of Asthma
}

\author{
John Johnson, Tina Abraham, Monica Sandhu, Devi Jhaveri, \\ Robert Hostoffer, and Theodore Sher
}

\section{Contents}

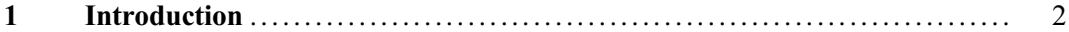

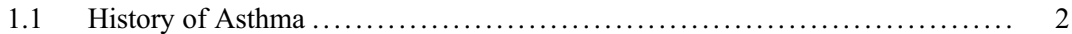

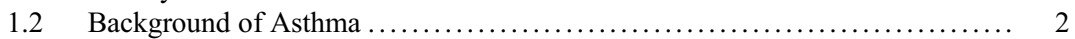

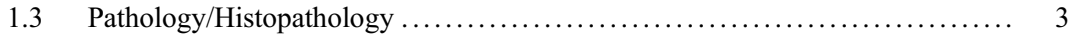

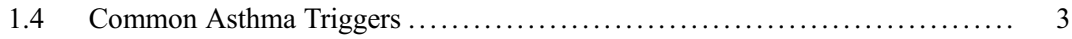

1.5 Chronic Obstructive Pulmonary Disease (COPD) $\ldots \ldots \ldots \ldots \ldots \ldots \ldots \ldots \ldots .4$

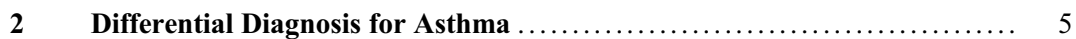

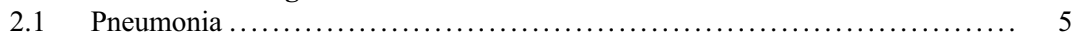

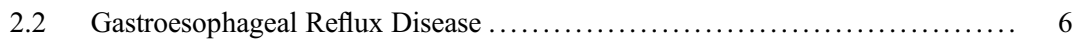

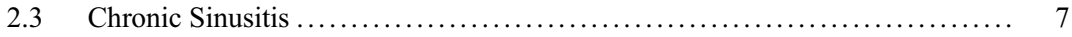

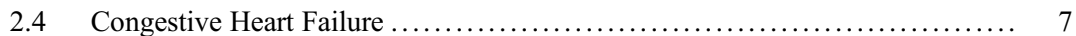

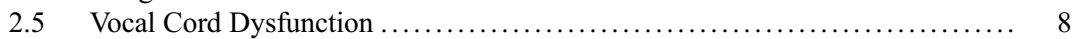

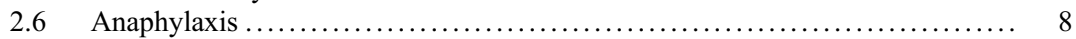

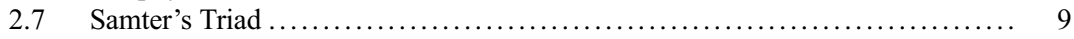

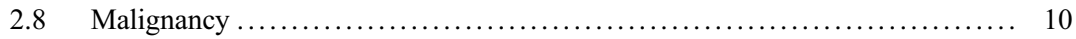

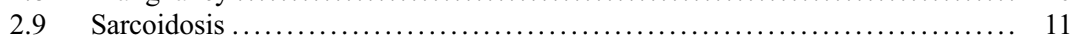

2.10 Hypersensitivity Pneumonitis . .................................. 11

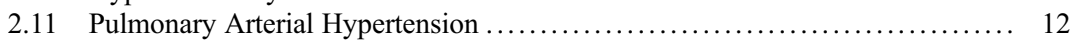

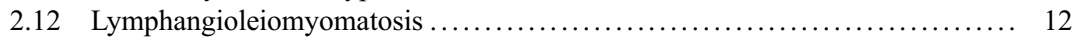

J. Johnson $(\bowtie) \cdot T$. Abraham $\cdot$ M. Sandhu

Department of Adult Pulmonary, University Hospitals

Cleveland Medical Center, Cleveland, OH, USA

e-mail: jajohn484@gmail.com; latinaabraham@gmail.com; monicaksandhu@gmail.com

D. Jhaveri · R. Hostoffer

Department of Adult Pulmonary, University Hospitals

Cleveland Medical Center, Cleveland, OH, USA

Allergy/Immunology Associates, Inc, Mayfield Heights,

$\mathrm{OH}$, USA

e-mail: r.hostoffer@gmail.com

T. Sher

Allergy/Immunology Associates, Inc, Mayfield Heights,

$\mathrm{OH}, \mathrm{USA}$

e-mail: morse98@aol.com 


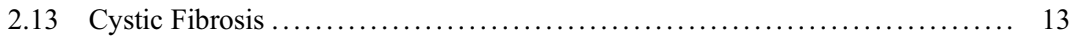

2.14 Eosinophilic Pulmonary Diseases ................................ 13

2.15 Eosinophilic Granulomatosis with Polyangiitis ............................. 14

2.16 Other Pulmonary Vasculitis Syndromes ........................... 14

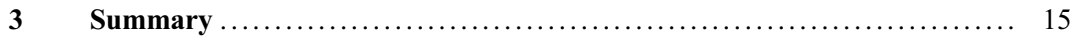

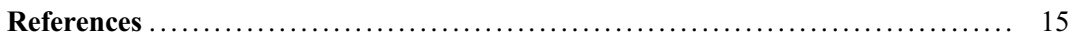

\section{Abstract}

Asthma is one of the most common chronic syndromes worldwide (Moorman et al., Vital Health Stat 3(35), 2012). It is not a diagnosis but a clinical syndrome based on a constellation of signs and symptoms ( $\mathrm{Li}$ et al., Ann Allergy Asthma Immunol 81:415-420(IIa), 1998). The classic symptoms of asthma include chest tightness, wheeze, cough, and dyspnea (Moorman et al., Vital Health Stat 3 (35), 2012). The term asthma encompasses a spectrum of pulmonary diseases sharing the hallmark of reversible airway obstruction and can be classified as allergic or non-allergic (Löwhagen, J Asthma. 52(6):538-44, 2015). Asthma designated allergic is due to an immunoglobulin E (IgE)-mediated process, but as noted not all asthma is allergic in etiology (Romanet-Manent et al., Allergy 57:607-13, 2002). The differential diagnosis for asthma is broad and requires a detailed history with supportive pulmonary function tests to be properly diagnosed.

\section{Keywords}

Asthma $\cdot$ Differential diagnosis ·

Pathophysiology

\section{Introduction}

\subsection{History of Asthma}

The word asthma is derived from the Greek verb, aazein, which means to pant (Marketos 1982). Hippocrates was the first to use asthma as a medical term referring to lung spasm in his teachings entitled, The Corpus Hippocraticum (Marketos 1982). In ancient China, inhaled preparations of ephedrine containing plants were used to stimulate beta-adrenergic receptors within the lung, which continues to be a mainstay mechanism for the treatment of asthma (Chang et al. 2013). In the 1860s, Dr. Henry Salter of London described the classic characteristics associated with asthma, such as airway hyperresponsiveness to cold and exercise, as well as environmental particulates (Sakula 1985).

\subsection{Background of Asthma}

Asthma is one of the most common chronic syndromes worldwide, and it is characterized by chronic inflammation of the pulmonary airway (Moorman et al. 2012). It is not a diagnosis but a clinical syndrome based on a constellation of signs and symptoms ( $\mathrm{Li}$ et al. 1998). The classic symptoms of asthma include chest tightness, wheeze, cough, and dyspnea, which may resolve spontaneously or in response to treatment (Moorman et al. 2012) (Table 1). Definitive criteria for the diagnosis of asthma do not exist (Li et al. 1998). The term asthma encompasses a spectrum of pulmonary diseases sharing the hallmark of reversible airway obstruction and can be classified as allergic or non-allergic (Löwhagen 2015). Asthma resulting from an IgE-mediated immunologic mechanism is designated allergic, while those not associated with IgE are classified as non-allergic and consist of many phenotypes (Romanet-Manent et al. 2002).

Table 1 Common symptoms of asthma

\begin{tabular}{l} 
Wheeze \\
\hline Cough \\
\hline Dyspnea \\
\hline Chest tightness \\
\hline
\end{tabular}




\subsection{Pathology/Histopathology}

The pathophysiology of asthma is characterized by reversible airway obstruction, non-specific airway hyperreactivity, and chronic inflammation (Kudo et al. 2013). Recurrent airflow limitation is driven by inflammatory mediators leading to bronchoconstriction, airway edema, hyperresponsiveness, and airway remodeling. Bronchoconstriction is the result of bronchial smooth muscle contraction in immediate response to an inhaled irritant or allergen (National 2007). While classically complete reversal of airway obstruction is indicative of asthma, many cases of asthma may only have a partial reversal in airflow and in some cases no reversal of obstruction. The fixed airway obstruction may in part be due to airway remodeling. Investigations are still underway to understand the exact pathophysiology of this; however, upregulation of growth factors by the bronchial epithelium seems to be the key in the persistent inflammation, smooth muscle hypertrophy, collagen production, neovascularization, basement membrane thickening, and increased myofibroblast and fibroblast activity (Busse et al. 2000).

In allergic asthma, activation of mast cells and $\mathrm{T}$ helper (Th2) cells by inhaled antigens leads to production and secretion of histamines, leukotrienes, and cytokines (National 2007). Key cytokines in this cascade include IL-4, IL-13, and IL-5, the latter of which is the primary signal for the differentiation of eosinophils. Eosinophils prolong and potentiate persistent airway inflammation by releasing leukotrienes, granule proteins, and GM-CSF. This is consistent with postmortem histopathology showing eosinophilic infiltration into the mucosa and the airway and mucous plugging of the airway lumen (Busse et al. 2000).

In all classifications of asthma severity, mild, moderate, or severe, there are consistent histopathologic changes. In both the proximal and distal airways, epithelial detachment, goblet cell hyperplasia, subepithelial fibrosis, infiltration of inflammatory mediators, bronchial smooth muscle hypertrophy, and vascular changes are all observed (Hamid 2003). Despite these consistent changes, the course of asthma is variable in its severity and progression over an individual's life and between individuals. For the majority of patients, asthma begins early in life with risk factors for development including atopic disease, recurrent wheezing, and parental history of asthma (2).

\subsection{Common Asthma Triggers}

Common asthma triggers are environmental factors such as air pollution, tobacco smoke, occupational exposures, indoor allergens (dust mites, molds, pets, rodents, and cockroaches) and outdoor allergens (tree, grass, and weed pollen), exercise, and infections (CDC 2012; Yang et al. 2017) (Table 2). Viral infections and airborne allergens are two of the most important environmental factors leading to asthma development, persistence, and possibly asthma severity (NHLBI 2007). Though allergens and other environmental factors are a strong trigger for many with asthma, complete avoidance is often impossible, and despite avoidance asthma often remains active. For those not responding to avoidance, treatment is based on symptom frequency and severity of disease. Quick relief medications are inhaled short-acting beta2-agonists and anticholinergics. Long-term control medications are used to treat persistent asthma and include inhaled long-acting beta2- agonists, anticholinergics, corticosteroids, cromolyn sodium, and oral leukotriene modifiers and methylxanthines. Those that fail to respond to conventional therapy noted above may respond to biologic agents depending on their phenotypic classification of asthma (AAAAI 2017). Allergen immunotherapy is also an option when there is a clear association between asthma symptoms and perennial and/or seasonal allergens (NHLBI 2007).

Table 2 Common asthma triggers

\begin{tabular}{l}
\hline Perennial allergens \\
\hline Outdoor allergens \\
\hline Infections \\
\hline Occupational exposures \\
\hline Air pollution \\
\hline Exercise
\end{tabular}


Vaccination schedules should be adhered to in order to decrease infectious triggers.

\subsection{Chronic Obstructive Pulmonary Disease (COPD)}

Like asthma, the term COPD encompasses numerous phenotypes. One phenotype is chronic bronchitis, which is a diagnosis of exclusion characterized by a chronic cough occurring for 3 continuous months a year for at least 2 consecutive years (Monetes 2012). Emphysema is another subtype resulting from the permanent loss of alveoli (Montes de Oca et al. 2012). Without the alveoli the airway loses the recoil from the parenchyma necessary to keep the airway patent. The asthma-COPD overlap syndrome (ACOS) is a phenotype inclusive of both clinical syndromes (Foreman et al. 2007). The diagnosis of ACOS is clinical, and with most of the key symptoms being shared between pure COPD and asthma, it further adds to the challenge of accurately making this diagnosis (Saetta et al. 1994; Barnes 2002) (Fig. 1).
COPD is considered by most to be a less reversible obstructive airway disease; however, COPD can reverse and even to the same degree as asthma. The symptoms experienced by patients with COPD are common to asthma as well; these include wheezing, coughing, and dyspnea. Both diseases are diagnosed similarly by taking into account the patient's history as well as pulmonary function tests (PFTs). Chronic obstructive lung disease is defined by having a forced expiratory volume in $1 \mathrm{~s}$ (FEV1) to forced vital capacity (FVC) ratio of 0.7 or less after reversal with albuterol (Alpert et al. 2016).

Characteristics distinguishing COPD from asthma include failure to reverse to normal with therapy, a strong association with cigarette smoke or inhalation of smoke from indoor burning of organic material for cooking, and a reduced diffusing capacity of the lung for carbon monoxide (DLCO) (Stoller et al. 1994). Cigarette smoke exposure is dose-dependent making it important to determine the smoker's total pack-years (the number of cigarette packs smoked per day multiplied by the number of years the individual smoked) (Montes de Oca et al. 2012). Secondhand cigarette exposure is a risk factor as well,

Fig. 1 Asthma-COPD overlap syndrome

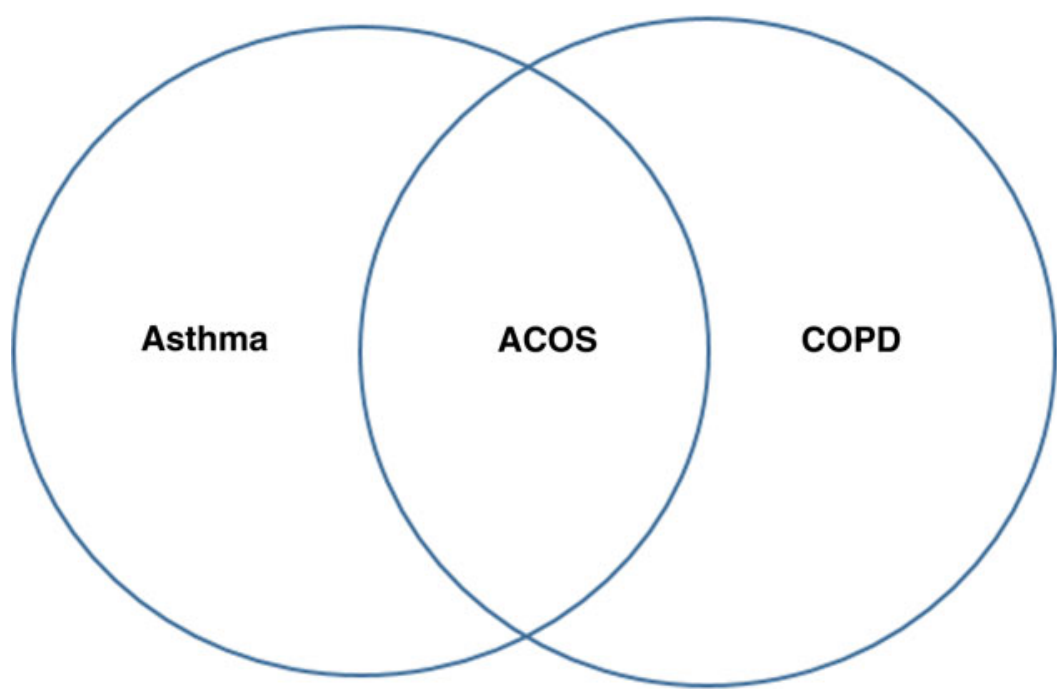


which has more recently gained significant recognition for its role in the development of COPD (Guerra et al. 2009).

Emphysema increases dead space ventilation by destroying the alveolar membranes. This leads to an imbalance in the amount of inhaled air relative to the surface area of the lung capable of gas exchange (Miravitlles et al. 2000). Emphysema may be ascertained by using a CT scan of the chest, demonstrating classic COPD findings of emphysema such as vast destruction and dilation of alveoli. By comparison in asthma, the alveoli are not destroyed, but instead air is trapped within the alveoli due to bronchial obstruction. The result in asthma is decreased ventilation, but the surface area capable of gas exchange remains intact with a normal DLCO (Miravitlles et al. 2000).

\section{Differential Diagnosis for Asthma}

\subsection{Pneumonia}

Patients given the diagnosis of asthma that is refractory to treatment should be evaluated for an alternative diagnosis (Aguilar et al. 2014) (Table 3). Acute respiratory symptoms, tachypnea, fever, or radiologic evidence of parenchymal infiltrates defines pneumonia. Pneumonia is often initiated by colonization of the nasopharynx with subsequent infection of the lower respiratory tract and can be caused by bacteria, viruses, or fungi (Browne 2010) (Table 4).

Viral etiologies are the main triggers for asthma exacerbations. Respiratory viruses are the etiologic agent in nearly $15 \%$ of all patients presenting with pneumonia (Johnstone et al. 2008). Viral causes of pneumonia include the influenza virus, especially during influenza outbreaks (Musher 2014). It is important to maintain a high index of suspicion for a secondary bacterial infection in these patients as well. Respiratory syncytial virus, parainfluenza virus, human metapneumovirus, adenovirus, coronavirus and rhinovirus can also be detected in patients with community acquired pneumonia (CAP) (Musher 2014). In children, respiratory viruses are the most
Table 3 The differential diagnosis of asthma

\section{Common}

\section{COPD}

Infectious etiologies
(1) Bacterial
(2) Viral
(3) Fungal

Gastroesophageal reflux disease (GERD)

Chronic rhinosinusitis (CRS)

Congestive heart failure (CHF)

Vocal cord dysfunction (VCD) and other disorders of the upper airway

Less frequent

Idiopathic anaphylaxis with predominant respiratory manifestations

Aspirin or nonsteroidal exacerbated respiratory disease (AERD or Samter's triad)

Malignancy

Sarcoidosis and other autoimmune processes

Hypersensitivity pneumonitis

Pulmonary hypertension

Drug induced bronchospasm

\section{Uncommon}

Lymphangioleiomyomatosis (LAM)

Cystic fibrosis

Loeffler's syndrome and other eosinophilic lung diseases Vasculitides

(1) Churg-Strauss vasculitis (eosinophilic granulomatosis with polyangiitis [EGPA])

(2) Wegener's granulomatosis (chronic granulomatosis with polyangiitis [GPA])

(3) Microscopic polyangiitis

common causes of pneumonia (Jain et al. 2015). Syndromes suggestive of a viral etiology are usually treated with symptomatic measures. If there are symptoms suggestive of influenza as the culprit, oseltamivir, a viral neuraminidase inhibitor, should be administered within the first $48 \mathrm{~h}$ of symptoms (Musher 2014).

Patients who develop acute lung infections, have not been recently hospitalized, and also do not have routine exposure to the health-care system fall under the category of communityacquired pneumonia (CAP) (Musher 2014). Common bacterial causes of CAP are Streptococcus pneumoniae (the most common), Haemophilus influenzae, and Staphylococcus aureus (Musher 2014). Mycoplasma pneumoniae, an atypical 
Table 4 Most common pneumonic etiologies with asthma-like symptoms

\begin{tabular}{l|l|l}
\hline Bacterial & Viral & Fungal \\
\hline $\begin{array}{l}\text { Streptococcus } \\
\text { pneumoniae }\end{array}$ & $\begin{array}{l}\text { Respiratory syncytial } \\
\text { virus (RSV) }\end{array}$ & $\begin{array}{l}\text { Histoplasma, sCoccidioidomycosis in } \\
\text { endemic areas }\end{array}$ \\
\hline $\begin{array}{l}\text { Haemophilus } \\
\text { influenzae }\end{array}$ & $\begin{array}{l}\text { Parainfluenza and } \\
\text { influenza virus }\end{array}$ & $\begin{array}{l}\text { Candida, Aspergillus, Zygomycetes } \\
\text { in ICU setting }\end{array}$ \\
\hline $\begin{array}{l}\text { Staphylococcus } \\
\text { aureus }\end{array}$ & $\begin{array}{l}\text { Human } \\
\text { metapneumovirus }\end{array}$ & \\
\hline $\begin{array}{l}\text { Mycoplasma } \\
\text { pneumoniae }\end{array}$ & & \\
\hline
\end{tabular}

species, has also been implicated and occurs in both early- and late-onset asthma (Yeh et al. 2016). Compared with typical bacterial pneumonia, atypical pneumonia usually presents with less severe symptoms, such as headache, malaise, and low grade fever, with a more gradual onset (Browne 2010). The mainstay of therapy for bacterial pneumonias is the administration of antimicrobial agents that are appropriate for the overall clinical condition of the patient and the suspected microorganism in question.

Uncommon causes of CAP can present as subacute infections due to fungal etiologies, such as Histoplasma and Coccidioides species in endemic areas. This type of an infection is characterized by cough, fever, and pulmonary infiltrates and should be treated with appropriate antifungal therapy (Musher 2014). Candida, aspergillus, and zygomycete are the main fungal isolates obtained from respiratory secretions of ICU patients (Shamim et al. 2015). While these more commonly occur in neutropenia, non-neutropenic patients with appropriate risk factors in the intensive care unit develop this type of pathology and should be treated with appropriate antifungal therapy as determined by the identified microorganism (Shamim et al. 2015).

\subsection{Gastroesophageal Reflux Disease}

Gastroesophageal reflux disease (GERD) classically presents with symptoms of persistent heartburn or metallic taste $(\mathrm{NIH})$; however, either of these symptoms is only present $40 \%$ of the time. Extraesophageal symptoms may include chronic cough, wheezing, bronchospasm, sore throat, laryngitis, and hoarseness (NIH, Badillo 2014). Symptoms of GERD may be triggered by a select number of foods and drinks such as coffee, chocolate, citrus fruits, tomato-based foods, spicy foods, fatty foods, and alcohol. GERD can present in several different ways and at times can resemble asthma as suggested by the extraesophageal manifestations. In some asthmatics, reflux serves as a potential trigger or contributing factor for asthma (Harding 1999). There is no gold standard diagnosis for GERD. Upper endoscopy shows characteristic esophageal changes in only $40 \%$ of cases (Nwokediuko 2012). GERD may be differentiated from asthma with $\mathrm{pH}$ probe and/or barium swallow (King 2008). However, there is no definitive test to reliably confirm the diagnosis of GERD. GERD can coexist with asthma in up to $80 \%$ of patients (Sontag 2006). Treatment of GERD should be pursued if the patient is symptomatic, although it does not appear that GERD worsens asthma (NEJM 2009;160:1487-1499).

Thus, the diagnosis is made predominantly on clinical suspicion in combination with medication trials. Patients with significant asthma symptom improvement with proton pump inhibitor therapy likely have GERD, but GERD treatment is ineffective for persistent asthma without GERD symptoms (NEJM 2009;160:1487-1499). Asthma should be considered when extraesophageal symptoms of cough, wheeze, and bronchospasm persist despite maximal GERD treatment. 


\subsection{Chronic Sinusitis}

Sinusitis is essential to the differential of asthma. Sinusitis exhibits respiratory symptoms similar to asthma, such as shortness of breath from extensive turbinate edema and cough from postnasal drip (Bucca et al. 1995). Additionally, both conditions share many inflammatory mediators, which may be triggered by infections and air pollution and by allergens in allergic subjects (Frieri 2003).

The prevalence of sinusitis is $15 \%$ of the population in the United States (Moss 1986). Symptoms include nasal congestion, sinus discharge, facial pressure, and diminished sense of smell (Wald et al. 2013). In addition to symptoms, for formal diagnosis patients must have evidence of sinus inflammation demonstrated by either endoscopy or computerized tomography (CT) scan (Wald et al. 2013). Sinusitis is termed chronic once the symptoms have been present for 12 weeks or longer (Wald et al. 2013). Chronic sinusitis often has longer duration but diminished severity of symptoms compared to acute sinusitis (Wald et al. 2013).

A variety of etiologies contribute to the syndrome of chronic sinusitis. Allergic rhinosinusitis due to perennial allergens is relatively common and associated with sneezing and itching (Williams 1996). Continuous exposure to perennial allergens such as dust mite, animal dander, mold, and cockroach contribute to the chronicity of the disease (Williams 1996). Intranasal corticosteroids are the treatment of choice for allergic rhinitis (Ratner et al. 2007). The most common isolates of bacterial sinusitis include Streptococcus pneumoniae, Haemophilus influenzae, and Moraxella catarrhalis (Zimmerman 1991). Amoxicillin, with or without clavulanate, is the first-line therapy for bacterial sinusitis (Lund 1194). Recurrent episodes of bacterial sinusitis should prompt an evaluation for immunologic and anatomic abnormalities (Zimmerman 1991).

\subsection{Congestive Heart Failure}

Congestive heart failure (CHF) is due to a variety of etiologies, which result in systolic or diastolic ventricular dysfunction (Figueroa 2006). The diagnosis is based on a thorough history and physical exam and supported by appropriate ancillary testing such as an echocardiogram, electrocardiogram, and chest X-ray (Figueroa 2006). CHF is the leading cause of acute dyspnea in elderly patients, and one-third of those affected experience cardiac wheezing, which could be confused with asthma (Jorge et al. 2007). In non-elderly patients, the rate of wheezing in patients with $\mathrm{CHF}$ is $10-15 \%$. On the basis of these statistics, CHF should be considered in the differential diagnosis of patients with dyspnea and wheezing.

The underlying pathophysiologic mechanism for a cardiac wheeze seems to arise from the left ventricular (LV) dysfunction itself. As LV function deteriorates, there is an increase in pulmonary vascular pressure, which causes a leakage of plasma into the interstitial space (Dominguez 2002). As the interstitial pressure rises, there is resultant narrowing of the bronchioles that in return causes impedance of the conducted air, resulting in the wheezing sound (Dominguez 2002). Diuresing these subjects presumably improves the clinical picture by reducing the extravascular lung water and overall general improvement in pulmonary and bronchial lung volumes (Jorge et al. 2007).

Once the diagnosis of CHF is made, treatment comprises both pharmacologic and non-pharmacologic measures. Pharmacologic treatment combines the use of afterload reduction with angiotensin-converting enzyme inhibitors, reduction catecholamine surges with beta-blockers, and preload reduction with diuretics for the relief of dyspnea and signs of water and sodium retention (Figueroa 2006). Non-pharmacologic treatments include ventricular synchronization via biventricular pacing devices as well as implantable defibrillators. The most important key in determining appropriate treatment for patients with CHF is to clinically stratify them in the appropriate New York Heart Association Classification system. This system provides a yardstick for the comparison of CHF treatment (Figueroa 2006). 


\subsection{Vocal Cord Dysfunction}

Vocal cord dysfunction (VCD) occurs when the vocal cords do not open properly or close inappropriately, particularly during inspiration. Specifically, there is inappropriate adduction of the vocal cords usually during inhalation caused by vocal cord hyperresponsiveness. Symptoms can resemble asthma, and the two diagnoses can be confused leading to misdiagnosis, inappropriate treatment, and persistence of uncontrolled respiratory symptoms (Dunn 2005; AAAAI 2017).

The clinical presentation of vocal cord dysfunction can vary from asymptomatic, to mild dyspnea, to symptoms suggesting an acute asthma exacerbation (Maillard et al. 2000). Symptoms of wheezing, hoarse voice, difficulty breathing, coughing, dysphagia, throat tightness, globus sensation, and chest pain can occur. Similar to asthma, VCD can be triggered by temperature changes, upper respiratory infections, emotional stressors, physical exertion or exercise, acid reflux, ingestion of specific foods, laughing, talking, singing, strong odors, and inhalation of respiratory irritants (Andrianopoulos et al. 2000; Morrison et al. 1999). Features that may distinguish VCD from asthma are inspiratory wheeze triggered by odors, dysphonia, and throat tightness. Further, there is no absolute distinguishing feature between VCD and asthma if the two disorders coexist (AAAAI 2017).

The diagnosis of VCD should begin with a thorough clinical history and physical exam to assess for characteristic features. Often, patients will point to their throat when asked where symptoms originate. The vocal cord dysfunction questionnaire (VCDQ) is a 12-item questionnaire developed by Fowler and colleagues that may help assess severity and symptom improvement. This instrument demonstrates improvement in scores following speech therapy (Fowler et al. 2015). The Pittsburgh VCD index is another tool developed by Traister and colleagues to help distinguish between VCD and asthma. Scores are assigned based on symptoms of throat tightness (score of 4), dysphonia (score of 2), absence of wheezing (score of 2), and presence of odors as a trigger (score of 3 ). A score $\geq 4$ is $83 \%$ sensitive and $95 \%$ specific for the diagnosis of VCD (Traister et al. 2014).

Spirometry may help differentiate VCD and asthma. Flattening, sawtooth pattern, and/or truncation may be seen on the inspiratory flow loop indicating a variable extrathoracic obstruction (Balkissoon 2002; Miller 1973). These characteristics may occur while the patient is asymptomatic but are more likely during an acute VCD attack (Balkissoon 2002).

Laryngoscopy showing paradoxical vocal fold movement on inhalation is the gold standard for the diagnosis of VCD. Although, between attacks, the vocal cords may be normal, the condition cannot be excluded by a normal examination when symptoms are minimal or absent. In severe cases, the airway can become so compromised that only a small star-shaped orifice, often termed "chink," may be available for inhalation leading to acute respiratory distress. Treatment of VCD focuses on patient reassurance of the benign nature of the condition, speech therapy and deep breathing techniques, all of which may reduce the laryngeal hyperreactivity. Inappropriate, highdose inhaled therapy, particularly with corticosteroids, may contribute to the condition by irritating the larynx or result in reversible laryngomalacia.

\subsection{Anaphylaxis}

Anaphylaxis is a systemic, potentially lifethreatening, immediate reaction that is most commonly induced by allergy to medication or foods. This is classically the result of an IgE-mediated mechanism that may affect the cutaneous, respiratory, cardiovascular, and gastrointestinal systems. Anaphylactic events can resemble asthma if respiratory symptoms precede other organ system manifestations. Approximately $40-60 \%$ of anaphylactic reactions present with respiratory manifestations, such as shortness of breath, wheeze, and nasal congestion. It is therefore important to perform a thorough physical examination as well as obtain an adequate history to distinguish between this multisystem, lifethreatening reaction and an acute asthmatic attack. Subjects with asthma are at risk of more severe 
anaphylaxis, particularly if the asthma is not well controlled at the time of the anaphylaxis.

Exercise-induced anaphylaxis (EIA) may be misdiagnosed as an exercise-induced asthma. The trigger of exercise-induced may not be obvious, since it is inconsistently reproducible. EIA occurs when a patient engages in rigorous physical activity and the symptoms progress with the duration of activity. A subset of EIA is the fooddependent, but the majority of EIA episodes are non-food-dependent. In food-dependent EIA, the trigger is more elusive, since the patient must exercise within $4-6 \mathrm{~h}$ of ingesting a specific food. The initial symptoms may include wheezing and dyspnea although other manifestation may soon follow, including pruritus, urticaria, and dizziness, or other manifestations of hypotension. An accurate history of the events before, during, and after the reaction is necessary to differentiate EIA from exercise-induced asthma.

Idiopathic anaphylaxis is in the differential diagnosis of patients suspected of having asthma. Both conditions can present with acute onset of dyspnea, wheezing, cough, anxiety, and a sense of impending doom (Simons et al. 2011). Classically, anaphylaxis refers to a systemic, IgE-mediated hypersensitivity reaction due to the release of mediators from basophils and mast cells (Johansson et al. 2006). Anaphylaxis is a clinical diagnosis and does not require specific testing for confirmation, but identification of specific- $\operatorname{IgE}$ to culprit causes is necessary to establish allergic anaphylaxis (Bacal et al. 1978). The term idiopathic anaphylaxis refers to the absence of identifiable triggers to account for the often multiple, systemic reactions (Kemp et al. 1995). This may cause clinicians to overlook anaphylaxis as the etiology of a patient's symptoms, since a history of exposure to a typical allergen is not reported.

Idiopathic anaphylaxis is a diagnosis of exclusion, as is true for all idiopathic disorders. While the exact incidence is unknown, it is estimated to affect 20,592-47,024 individuals annually in United States (Patterson et al. 1995). It is more common among adults than in children and women more than men. Approximately $50 \%$ of subjects with idiopathic anaphylaxis are atopic (Patterson et al. 1995). While by definition subjects with idiopathic anaphylaxis have no identifiable cause for their anaphylactic reactions, eventually exercise and certain foods are identified as triggers in $11 \%$ and $5 \%$ of cases, respectively (Ditto et al. 1996). Other organic, systemic diseases involving mast cells must be considered as well; for instance, up to $50 \%$ of those initially diagnosed with idiopathic anaphylaxis ultimately are found to have systemic mastocytosis (Akin et al. 2007).

The management of idiopathic versus non-idiopathic anaphylaxis is significantly different. The goal is to prevent future reactions from occurring through medical management in idiopathic anaphylaxis, as opposed to avoidance of known triggers in non-idiopathic anaphylaxis (Blatman et al. 2012). Patients can be treated with prophylactic $\mathrm{H} 1$ and $\mathrm{H} 2$ antagonists for long-term control and in rare cases with the addition of systemic corticosteroids (Blatman et al. 2012; Wong et al. 1991). These patients should also be prescribed epinephrine auto-injectors, the only effective treatment for anaphylaxis. Preliminary data for the use of omalizumab, an anti- $\operatorname{IgE}$ monoclonal antibody, is promising (Warrier et al. 2009). The successful use of rituximab, a monoclonal antibody specific for B lymphocytes, to induce remission has also been reported (Borzutzky et al. 2014).

\subsection{Samter's Triad}

Aspirin-exacerbated respiratory disease (AERD) is often referred to as Samter's triad. This triad includes asthma, sinus disease with recurrent nasal polyposis, and sensitivity to aspirin and other nonsteroidal anti-inflammatory drugs (NSAIDs) (Pongdee 2017). The hallmark of this chronic medical condition is exacerbation of upper and/or lower airway disease following the ingestion of aspirin or other NSAIDs (Aguilar et al. 2014). These reactions may include nasal congestion, frontal headache, sinus pressure, coughing, wheezing, chest tightness, and less commonly skin flushing, rash, abdominal pain, or vomiting (Pongdee 2017). Because of the predominant respiratory symptoms of wheezing and 
chest tightness, most experts consider AERD as a phenotype of asthma rather than a separate diagnosis.

Epidemiologically, 9\% of all asthmatics and $30 \%$ of patients with asthma and concurrent nasal polyps have AERD (Pongdee 2017). Patients with this condition commonly develop symptoms in adulthood, between the ages of 20 and 50 years (Pongdee 2017; Aguilar et al. 2014). Usually these patients will present with adult onset asthma that is preceded by years of sinonasal symptoms (Aguilar et al. 2014).

The primary mediators of AERD inflammation are in the arachidonic acid pathway. Arachidonic acid is metabolized by either cyclooxygenase to yield prostaglandins or by lipoxygenase to yield proinflammatory cysteinyl leukotrienes, which are significantly overproduced in patients with AERD (Aguilar et al. 2014; Laidlaw 2013). The relative excess of cysteinyl leukotrienes and prostaglandin-D2 leads to a shift toward a pro-inflammatory state (Laidlaw 2013; Moebus 2012). The inhibition of PgE2 may be the explanation for the rapid deterioration with the ingestion of NSAIDs.

The diagnosis of AERD is confirmed with an oral aspirin challenge and may be treated with aspirin desensitization which involves dose escalation into a therapeutic range, 325-650 mg bid, and then continued daily (Aguilar et al. 2014). The goals of desensitization are to control upper and lower respiratory symptoms, reduce the use of systemic corticosteroids, decrease the rate of growth and recurrence of nasal polyps, and improve the patient's quality of life (Moebus 2012). Continual aspirin therapy decreases bronchial hyperreactivity and improves nasal symptoms in addition to reducing polyp growth.

The asthmatic patient who does not respond to traditional asthma therapies and is difficult to control should be evaluated for AERD (Aguilar et al. 2014). These patients can experience severe exacerbations and often require control with inhaled corticosteroids, leukotriene modifying drugs, as well as aspirin desensitization (Aguilar et al. 2014; Moebus 2012).

\subsection{Malignancy}

Malignancies may resemble asthma and in some cases mask the underlying diagnosis. It is important to consider malignancy as a differential diagnosis in patients with persistent respiratory symptoms despite adequate asthma therapy.

Lung cancer accounts for 1.3 million deaths worldwide (WHO 2003). Lung parenchyma has limited sensory innervation, and primary lung cancers may reach a considerable size before becoming symptomatic (Ganie et al. 2013). The most common early symptom is cough, which occurs due to bronchial irritation or obstruction in up to $70-90 \%$ of patients. Dyspnea occurs in approximately $60 \%$ of patients as an early symptom. Hemoptysis can result from ulceration of bronchial tissue from tumor invasion or tumor necrosis and is an early symptom in $25-40 \%$ of patients. Wheezing can occur in $2-10 \%$ of lung cancer patients due to partial bronchial obstruction, usually from a hilar tumor (Ganie et al. 2013).

Carcinoid tumors are rare, occurring in 1.9 per 100,000 , are slow growing, and may be either benign or malignant (Crocetti 2003). Pulmonary carcinoid tumors compromise $2-5 \%$ of all lung cancers and are most commonly located centrally in the main or lobar bronchi (Hage et al. 2003; Filosso et al. 2002). Symptoms of pulmonary carcinoid tumors include hemoptysis, cough, wheezing, dyspnea, and lower respiratory tract infections (Schrevens et al. 2004; Zuetenhorst 2005). There is typically a delay in onset of symptoms to time of diagnosis, and patients are often misdiagnosed with asthma (Walusiak 2002; Dipaolo 1993; Wynn et al. 1986). Diffuse idiopathic pulmonary neuroendocrine hyperplasia (DIPNECH) is classified as a premalignant condition. It causes wheezing, cough, and dyspnea with relatively poor response to inhaled therapy but with improvement in systemic corticosteroids. Thus, this premalignant lung condition may be confused with asthma. Octreotide or other somatostatin analogs can reduce symptoms. 


\subsection{Sarcoidosis}

Pulmonary sarcoidosis is in the differential diagnosis of suspected asthma. Sarcoidosis can present with dyspnea and cough, thereby mimicking asthma (Ungprasert 2017). Sarcoidosis is a noncaseating, granulomatous disease involving multiple organ systems (Iannuzzi et al. 2007; Thomas 2003). The annual incidence rate for sarcoidosis is 35.5-70 per 100,000 among African-Americans versus 5-19 per 100,000 among Caucasians (Thomas 2003; Ungprasert 2017; Ungprasert et al. 2016). Ninety-seven percent will have evidence of intrathoracic sarcoidosis, and $43 \%$ will have respiratory symptoms (Ungprasert et al. 2016). A definitive diagnostic test does not exist for sarcoidosis. It is a diagnosis of exclusion, and it is dependent on clinical, radiographic, and histopathologic findings consistent with the disease (Judson 2012).

The pathogenesis of sarcoidosis has been extensively studied; however, the inciting etiologic stimulus has not been established (Iannuzzi et al. 2007; Thomas 2003). The majority of sarcoidosis patients have pulmonary involvement, which accounts for a majority of morbidity and mortality (Iannuzzi et al. 2007; Thomas 2003). The initial pulmonary lesions are comprised of CD4+ $\mathrm{T}$ cells, and they subsequently develop into the classic noncaseating granulomas characteristic of sarcoidosis (Tazi et al. 1992; Lecossier et al. 1991).

Many patients with sarcoidosis do not require treatment (Iannuzzi et al. 2007). Patients with severe pulmonary disease are treated to reduce the granulomatous inflammation and the development of irreversible lung damage (Iannuzzi et al. 2007). Glucocorticoids can be used as an initial therapy after the presence of Mycobacterium tuberculosis is excluded (Baughman et al. 2008). Prednisone at a maintenance dose of $0.25-0.4 \mathrm{mg} /$ $\mathrm{kg}$ may prevent progression of disease (Baughman 2015). Experts recommend a minimum of 3-6 months of therapy to prevent relapse (Wijsenbeek 2015). Most patients will respond to glucocorticoid therapy.

Patients who do not respond to glucocorticoids will require alternative immunosuppressive agents (Baughman 2004). Alternative agents should be considered when sarcoidosis progresses despite adequate glucocorticoid therapy or when patients cannot tolerate or refuse glucocorticoids (Sharma 1993). Methotrexate is the most commonly used alternative but is avoided in liver disease (du Bois 1994). Other immunosuppressive agents such as azathioprine, leflunomide, or TNF-alpha antagonists can be considered as options (du Bois 1994).

\subsection{Hypersensitivity Pneumonitis}

Hypersensitivity pneumonitis (HP) is a respiratory syndrome in the differential diagnosis of asthma. The clinical overlap with asthma is due to great variability in symptom, severity, and clinical presentation of the various stages of the disease. Hypersensitivity pneumonitis, also known as extrinsic allergic alveolitis, is the result of an inflammatory response from repeated exposure to a variety of antigenic particles in the environment. These particles affect the lung parenchyma, specifically the alveoli, terminal bronchiole, and alveolar interstitium (Sforza 2017; Ohshimo et al. 2012). The dispersed antigens must be a size that is appropriate for reaching the alveolar spaces (5 $\mu \mathrm{m}$ or less) (Selman 2012). These antigens include mammalian and avian proteins, fungi, thermophilic bacteria, and chemical compounds that can combine with host proteins to form haptens (Selman 2012). These same antigens can be the cause or trigger of asthma, and this can add to the difficulty of distinguishing between the two diseases.

The clinical presentation of HP is classified into acute, subacute, and chronic stages (Ohshimo et al. 2012). The acute form presents with a flu-like prodrome including fevers, chills, and malaise with concomitant respiratory features of cough, dyspnea, chest tightness, and tachypnea. These symptoms usually present $4-12 \mathrm{~h}$ after exposure to the antigen (Ohshimo et al. 2012). Acutely, this disease stage is nonprogressive and improves with antigen avoidance; however, it recurs following reintroduction of the etiologic antigen (Ohshimo et al. 2012). 
The subacute form usually results from continuous, low-level exposure to the antigen and is usually the result of progression from undiagnosed acute HP (Selman 2012). Clinical findings include dyspnea and productive cough progressing over weeks. In this subacute stage, fatigue, anorexia, and weight loss are also common (Selman 2012).

Chronic HP may be the result of continued low level exposure to inhaled antigens from either unrecognized acute or subacute episodes, known as recurrent chronic HP. Insidious chronic HP would describe patients without a previous history of acute HP. These patients experience progressive dyspnea on exertion, cough, fatigue, malaise, and weight loss, and the condition often progresses to diffuse fibrosis and end-stage lung disease.

The pathophysiology of this disease process is not clearly understood; however, it seems to be due to both humoral and cellular mechanisms (Selman 2012). In the acute phase, inflammation is due to immune complex-mediated reactions with high titers of antigen-specific serum immunoglobulin G, termed precipitins, and elevated neutrophils. Subacute and chronic HP has an amplified T-cell-mediated immune response (Selman 2012). Migration, proliferation, and decreased apoptosis of lymphocytes contribute to the pathogenesis of the classic T-lymphocytic alveolitis. HP is classically understood to be a Th1 disease (Ohshimo et al. 2012). However, the evolving fibrosis seen in the chronic forms of HP may be driven by a Th2 mechanism. Understanding of the mechanism of HP is evolving, and further studies are needed to explain why this disease develops in a minority of exposed individuals (Ohshimo et al. 2012).

The diagnosis of HP relies on a thorough history and physical examination with particular attention to the environmental and occupational history (Sforza 2017; Ohshimo et al. 2012). While there are several diagnostic criteria that have been proposed, none have been validated. Therefore, a high level of clinical suspicion, recognition of inhaled antigen exposure, and relevant clinical investigations including imaging, laboratory, and pathologic findings help to confirm the diagnosis of HP (Ohshimo et al. 2012).

\subsection{Pulmonary Arterial Hypertension}

The symptoms of pulmonary arterial hypertension (PAH) can be misinterpreted as asthma. Symptoms of PAH include breathlessness, dyspnea on exertion, cardiac palpitations, fatigue, syncope, and chest discomfort. PAH is an incurable and progressive disease characterized by elevated pulmonary arterial pressures leading to right ventricular failure (Chin 2008). A personal history of heart disease, congenital heart defects, scleroderma, and HIV and family history should be assessed, as these may contribute to PAH.

The physical examination may show signs of right heart failure, such as lower extremity edema and prominent jugular veins. Echocardiogram is used as a screening tool to assess ventricular function, while right ventricular catheterization remains the gold standard for diagnosis (Rich 2014). The hemodynamic diagnostic criteria for PAH include a mean pulmonary arterial pressure of $>25 \mathrm{mmHg}$, pulmonary capillary wedge or left ventricular end-diastolic pressure $<15 \mathrm{~mm} \mathrm{Hg}$, and pulmonary vascular resistance $>3$ Wood units (Chin 2008).

\subsection{Lymphangioleiomyomatosis}

Lymphangioleiomyomatosis is a progressive, rare cystic lung disease that predominantly affects young women of reproductive age (Pais 2017). As respiratory findings are common, this disease process is in the differential diagnosis of asthma, especially in the premenopausal female. LAM should be considered in a patient with dyspnea, cough, and chest pain (Johnson et al. 2016; Zhou et al. 2016). LAM can often mimic COPD, asthma, and bronchitis, which may lead to a delay in diagnosis. The natural course of this disease is usually varied, and affected women are at high risk of developing pneumothorax, rapid decline of lung function, progressive respiratory failure, and death (Taylor; Johnson et al. 2016).

The lung lesions in LAM are identified on chest CT and appear as numerous scattered 
thin-walled cysts that are evenly distributed throughout all lung fields (Johnson et al. 2016). Histologically, the lung lesions are small clusters of proliferated smooth muscle-like cells that are distributed along the peripheral vessels, bronchioles, and lymphatics (Taylor et al. 1990). Due to these changes, the conducting airways are compressed and obstructed causing the clinical respiratory findings described above.

To diagnose LAM, a thorough history and physical examination are combined with findings of angiolipomas and lymphatic disease on chest CT. Serum VEGF-D testing may be helpful, and lung biopsies may be employed if other clinical information is inconclusive (Johnson et al. 2016; Zhou et al. 2016). Once the diagnosis has been made, the patient should undergo a complete pulmonary function test and receive pneumococcal and influenza vaccinations, pulmonary rehab, and appropriate drug treatments with bronchodilators if obstructive symptoms are present (Johnson et al. 2016; Zhou et al. 2016; Taylor et al. 1990). Patients should also be made aware of the potential risks associated with the role of estrogen in this disease and take appropriate precautions in terms of estrogen containing pharmacotherapies (Johnson et al. 2016; Taylor et al. 1990). Once the diagnosis of LAM has been established, patients should be managed closely by a pulmonary team and be made aware of the chronicity of the disease (Johnson et al. 2016).

\subsection{Cystic Fibrosis}

Cystic fibrosis can mimic asthma due to coughing and dyspnea similar to asthma. It is an autosomal recessive disorder. Currently there are 30,000 people in the United States living with cystic fibrosis, and approximately 1000 new cases are diagnosed each year. More than $75 \%$ of patients are diagnosed with the disorder by the age of 2 years because of newborn screening programs (Cystic Fibrosis News Today 2017).

Cystic fibrosis is caused by a mutation in the cystic fibrosis transmembrane conductance regulator (CFTR) gene. This gene regulates anion transport and mucociliary clearance in the airways. Due to the dysfunction of the CFTR gene, mucous retention leads to chronic infections and local airway inflammation. This often results in progressive lung damage and decreased life expectancy (Elborn et al. 1991).

Symptoms include salty tasting skin, persistent coughing with production of thick mucus, wheezing, dyspnea, frequent sinusitis, bronchitis and pneumonia, digestive problems including malabsorption, and failure to gain weight (NIH 2017).

All newborns in the United States are screened for cystic fibrosis via genetic testing or blood test. If these tests suggest cystic fibrosis, the diagnosis is then confirmed with a sweat test. Goals of treatment focus on decreasing infections, pulmonary hygiene, and optimizing digestive health.

\subsection{Eosinophilic Pulmonary Diseases}

Pulmonary eosinophilia encompasses a group of heterogeneous diseases. These diseases must be considered in the differential of asthma, since they may present with dyspnea, wheezing, and cough (Loffler 1956). Eosinophilic lung disease may be characterized by peripheral eosinophilia with supportive pulmonary radiographic findings, eosinophils demonstrated on lung biopsy, or increased eosinophils in a bronchoalveolar lavage (BAL) (Allen 1994; Bain 1996). Peripheral eosinophilia with an absolute eosinophil count of 500 cells per microliter or greater supports an eosinophilic pulmonary disease (Valent et al. 2012). The degree of eosinophilia does not enable diagnosing the precise etiology (Umeki et al. 1992). A highresolution CT scan of the chest can provide significant findings early in the course of the disease (Johkoh et al. 2000). Löffler syndrome is one of many diseases classified as an eosinophilic pulmonary disease. It occurs when helminth larvae migrate to the lungs of an infected individual to mature before ascending the airways and return to the gastrointestinal tract (Wilson 2006). There are four types of helminths with life cycles within the lung: Ascaris lumbricoides, Ancylostoma duodenale, Necator americanus, and Strongyloides stercoralis (Wilson 2006). 
The syndrome was originally described by Löffler when patients presented with fleeting pulmonary opacities with peripheral eosinophilia after being exposed to soil contaminated with human waste (Löffler 1956).

Chronic eosinophilic pneumonia (CEP) is characterized by increased pulmonary eosinophils (Jederlinic et al. 1988). It is an idiopathic disease occurring predominantly in non-smokers and women (Marchand et al. 1998). Symptoms of weight loss and night sweats may occur in addition to respiratory symptoms and laboratory findings, which mimic asthma. In addition to mimicking asthma, 50\% of cases of CEP will have a concurrent or historical diagnosis of asthma (Jederlinic 1998). Peripheral eosinophilia is a typical feature and is present in up to $90 \%$ of cases (Marchand et al. 1998). A virtually pathognomonic finding on chest X-ray is peripheral pulmonary infiltrates, described as the photographic negative of pulmonary edema, and may be observed in up to one-third of CEP cases (Jederlinic 1998). The clinical diagnosis of CEP is based on the combination of peripheral or BAL eosinophilia, subacute presentation, and characteristic radiographic findings (Jederlinic 1998). CEP is treated with corticosteroids.

\subsection{Eosinophilic Granulomatosis with Polyangiitis}

Churg-Strauss syndrome (CSS), also known as eosinophilic granulomatosis with polyangiitis, is a rare, granulomatous eosinophilic vasculitis. It is characterized by a diffuse necrotizing vasculitis with extravascular granulomas seen almost exclusively in patients with asthma and tissue eosinophilia (Greco et al. 2015). Treating difficult to control asthma with corticosteroids can mask this diagnosis. Given the increased mortality in delaying the diagnosis until the active vasculitis phase, clinicians should keep the diagnosis of Churg-Strauss in the differential diagnosis of asthma (D’Cruz 1999; Aguilar 2014).

Churg-Strauss classically follows a triphasic pattern. The first phase is the initial prodrome and consists of upper airway disease such as rhinosinusitis with asthma. The second phase is the eosinophilic phase, characterized by significant peripheral eosinophilia and myocardial, pulmonary, and gastrointestinal involvement. The final phase is the vasculitis phase. This phase is the progression of the disease to multisystem, small vessel vasculitis (Greco et al. 2015; D’Cruz et al. 1999; Aguilar et al. 2014).

Patients with CSS typically present with dyspnea, cough, and wheeze that is refractory to traditional asthma treatment or a peripheral manifestation of vasculitis in a subject with a history of asthma. The diagnosis of CSS relies on radiologic, laboratory, and pathologic findings. CSS is a small vessel vasculitis that is associated with perinuclear-antineutrophil cytoplasmic antibody (p-ANCA) in approximately $40 \%$ of patients. The antigen recognized by the autoantibody is usually myeloperoxidase (MPO). The absence of ANCA does not exclude the diagnosis (Greco et al. 2015; Aguilar et al. 2014). Four or more of the following criteria aid in the diagnosis of CSS: presence of asthma, greater than $10 \%$ peripheral eosinophilia, mononeuropathy multiplex or polyneuropathy, nonfixed lung infiltrates, sinus abnormalities, and extravascular eosinophils on tissue biopsies, particularly in blood vessel walls or perivascular localization (Aguilar et al. 2014). Some authors suggest that any patient with asthma and concurrent features of multisystem disease should be considered to have an underlying vasculitis such as CSS (D’Cruz et al. 1999).

\subsection{Other Pulmonary Vasculitis Syndromes}

The triad of Wegener's granulomatosis, or granulomatosis with polyangiitis (GPA), consists of necrotizing granulomatous inflammation of the upper and lower airways, necrotizing glomerulonephritis, and an autoimmune necrotizing vasculitis (Lamprecht 2004). GPA is a vasculitis affecting medium- and small-sized vessels.

GPA usually presents in middle age but can occur in older adults. It is rare in childhood. This disease can affect almost any site in the body; however, the classic sites of involvement include 
the upper respiratory tract, lungs, and kidneys. Patients may present with a multitude of complaints such as fever, fatigue, unintentional weight loss, hearing changes, recurrent sinusitis, persistent rhinorrhea, eye problems, nasal crusts and ulcerations, epistaxis caused by local inflammation, dyspnea and hoarseness caused by subglottic stenosis, cough with bloody sputum, wheezing caused by upper or lower airway inflammation, joint pain, and hematuria.

The diagnosis may be delayed by months because early clinical symptoms of GPA are similar to milder and more common respiratory problems. The combination of c-ANCA (cytoplasmicANCA)/anti-proteinase 3 (PR3) $(\sim 80 \%)$ or p-ANCA/anti-MPO (10-15\%) has high specificity $(>95 \%)$ for the diagnosis of GPA. The diagnosis of GPA is confirmed with biopsy. Tissue from the upper respiratory tract can be obtained with less risk; however, the yield of upper airway biopsies is relatively low. Lung biopsy or renal biopsy, if kidney involvement suspected, is often the best way to diagnose this disorder. Treatment is focused on long-term immunosuppression.

Microscopic polyangiitis is another systemic vasculitis with pulmonary involvement. Generally the manifestation is dyspnea and cough with generalized alveolitis and alveolar hemorrhage. The CT scan usually demonstrates ground-glass changes rather than nodules as is typical of GPA. Microscopic polyangiitis is usually ANCA positive, although not as reliably as GPA. Eosinophilia is not typical with microscopic polyangiitis and it is not associated specifically with asthma. As with all vasculitic syndromes, the diagnosis requires tissue biopsy demonstrating small artery and arteriole damage with hemorrhage.

\section{Summary}

Although asthma is very common, other disease states can mimic asthma as emphasized in this chapter. The cardinal symptoms of asthma, cough, shortness of breath, wheezing, and chest tightness, are shared with many disorders, which can be confused with asthma or which may complicate asthma. Careful attention to history as well as the physical examination and selected imaging, spirometry, and/or laboratory facilitates the appropriate classification and diagnosis in the subject with suspected asthma. Corticosteroid therapy typically used for asthma may improve many of the conditions in the differential diagnosis. Clinical vigilance is essential, particularly when the clinical course is atypical for asthma or fails to resolve with appropriate asthma therapy.

\section{References}

Achouh L, Montani D, Garcia G, Jais X, Hamid AM, Mercier O, ..., Humbert M. Pulmonary arterial hypertension masquerading as severe refractory asthma. Eur Respir J. 2008;32(2):513-6.

Aguilar PR, Walgama ES, Ryan MW. Other asthma considerations. Otolaryngol Clin N Am. 2014;47(1): 147-60.

Akin C, et al. Demonstration of an aberrant mast-cell population with clonal markers in a subset of patients with "idiopathic" anaphylaxis. Blood. 2007;110: 2331-3.

Allen JN, Davis WB. Eosinophilic lung diseases. Am J Respir Crit Care Med. 1994;150:1423.

Alpert RA, et al. A randomized trial of long-term oxygen for COPD with moderate desaturation. N Engl J Med. 2016;375(17):1617-27.

American Lung Association Asthma Clinical Research Centers. Efficacy of esomeprazole for treatment of poorly controlled asthma. N Engl J Med. 2009; 360(15):1487-99.

Andrianopoulos MV, Gallivan GJ, Gallivan KH. PVCM, PVCD, EPL, and irritable larynx syndrome: what are we talking about and how do we treat it? J Voice. 2000;14(4):607-18.

Bacal E, et al. Evaluation of severe (anaphylactic) reactions. Clin Allergy. 1978;8:295-304.

Badillo R, Francis D. Diagnosis and treatment of gastroesophageal reflux disease. World $J$ Gastrointest Pharmacol Ther. 2014;5(3):105.

Bain GA, Flower CD. Pulmonary eosinophilia. Eur J Radiol. 1996;23:3.

Balkissoon R. Occupational upper airway disease. Clin Chest Med. 2002;23(4):717-25.

Barnes PJ. Ann Ist Super Sanita. 2003;39:573-82.

Baughman RP. Pulmonary sarcoidosis. Clin Chest Med. 2004;25:521.

Baughman RP, Grutters JC. New treatment strategies for pulmonary sarcoidosis: antimetabolites, biological drugs, and other treatment approaches. Lancet Respir Med. 2015;3:813.

Baughman RP, Costabel U, du Bois RM. Treatment of sarcoidosis. Clin Chest Med. 2008;29:533.

Billah MM. J Pharmacol Exp Ther. 2002;302:127-37. 
Blatman KH, et al. Idiopathic anaphylaxis. Allergy Asthma Proc. 2012;33:S84-7.

Borzutzky A, et al. Induction of remission of idiopathic anaphylaxis with rituximab. J Allergy Clin Immunol. 2014;134:981-3.

Browne LR, Gorelick MH. Asthma and pneumonia. Pediatr Clin N Am. 2010;57(6):1347-56.

Bucca C, Rolla G, Brussino L, De Rose V, Bugiani M. Are asthma-like symptoms due to bronchial or extrathoracic airway dysfunction? Lancet. 1995;346(8978): 791-5.

Busse WW, Banks-Schlegel S, Wenzel SE. Pathophysiology of severe asthma. J Allergy Clin Immunol. 2000;106(6):1033-42.

Chang $\mathrm{H}$, et al. A nebulized complex traditional Chinese medicine inhibits histamine and IL- 4 production by ovalbumin in guinea pigs and can stabilize mast cells in vitro. BMC Complement Altern Med. 2013;13:174.

Chin KM, Rubin LJ. Pulmonary arterial hypertension. J Am Coll Cardiol. 2008;51(16):1527-38.

Common Asthma Triggers. (2012, August 20). Retrieved 24 Sept 2017, from https://www.cdc.gov/asthma/trig gers.html

Crocetti E, Paci E. Malignant carcinoids in the USA, SEER 1992-1999. An epidemiological study with 6830 cases. Eur J Cancer Prev. 2003;12(3):191-4.

Cystic fibrosis - Genetics Home Reference. (n.d.). Retrieved 24 Sept 2017, from https://ghr.nlm.nih.gov/ condition/cystic-fibrosis

Cystic Fibrosis Treatment, Therapy and New Medications \& Drug|CF News Today. (n.d.). Retrieved 24 Sept 2017, from https://cysticfibrosisnewstoday.com/

D'Cruz DP, Barnes NC, Lockwood CM. Difficult asthma or Churg-Strauss syndrome?: steroids may be masking undiagnosed cases of Churg-Strauss syndrome. BMJ: Br Med J. 1999;318(7182):475.

Dipaolo F, Stull MA. Bronchial carcinoid presenting as refractory asthma. Am Fam Physician. 1993;48(5): 785-9.

Ditto AM, et al. Idiopathic anaphylaxis: a series of 335 cases. Ann Allergy Asthma Immunol. 1996;77: 285-91.

Dominguez OJ Jr. Breathless. Emerg Med Serv. 2002; 31(4):87.

Drug Guide|AAAAI. (n.d.). Retrieved 25 Sept 2017, from http://www.aaaai.org/conditions-and-treatments/drugguide

du Bois RM. Corticosteroids in sarcoidosis: friend or foe? Eur Respir J. 1994;7:1203.

Dunn NM, Katial RK, Hoyte FC. Vocal cord dysfunction: a review. Asthma Res Pract. 2015;1(1):9.

Eden E, et al. Am J Respir Crit Care Med. 1997;156(1): 68-74.

Elborn JS, Shale DJ, Britton JR. Cystic fibrosis: current survival and population estimates to the year 2000 . Thorax. 1991;46(12):881-5.

Figueroa MS, Peters JI. Congestive heart failure: diagnosis, pathophysiology, therapy, and implications for respiratory care. Respir Care. 2006;51(4):403-12.
Filosso PL, Rena O, Donati G, Casadio C, Ruffini E, Papalia E, et al. Bronchial carcinoid tumors: surgical management and long-term outcome. $\mathrm{J}$ Thorac Cardiovasc Surg. 2002;123(2):303-9.

Foreman MG, et al. Eur Respir J. 2007;30:1124-30.

Fowler SJ, Thurston A, Chesworth B, Cheng V, Constantinou P, Vyas A, et al. The VCDQ-a questionnaire for symptom monitoring in vocal cord dysfunction. Clin Exp Allergy. 2015;45(9):1406-11.

Frieri M. Interaction between rhinitis and asthma: state of the art. Allergy Asthma Proc. 2003;24(6):385-93.

Ganie FA, Wani ML, Lone H, Wani SN, Hussain SA. Carcinoma lung: clinical presentation, diagnosis, and its surgical management. J Assoc Chest Phys. 2013;1(2):38.

Gastroesophageal Reflux Disease - National Library of Medicine - PubMed Health. (n.d.). Retrieved 24 Sept 2017, from https://www.ncbi.nlm.nih.gov/ pubmedhealth/PMH0001311/

Gastroesophageal Reflux Disease|AAAAI. (n.d.). Retrieved 24 Sept 2017, from http://www.aaaai.org/ conditions-and-treatments/related-conditions/gastro esophageal-reflux-disease

Greco A, Rizzo MI, De Virgilio A, Gallo A, Fusconi M, Ruoppolo G, et al. Churg-strauss syndrome. Autoimmun Rev. 2015;14(4):341-8.

Guerra S, et al. Chronic bronchitis before age 50 years predicts incident airflow limitation and mortality risk. Thorax. 2009;64:894-900.

Hage R, de la Rivière AB, Seldenrijk CA, Van den Bosch JMM. Update in pulmonary carcinoid tumors: a review article. Ann Surg Oncol. 2003;10(6):697-704.

Hamid Q. Gross pathology and histopathology of asthma. J Allergy Clin Immunol. 2003;111(2):431-2.

Harding SM. Gastroesophageal reflux and asthma: insight into the association. J Allergy Clin Immunol. 1999; 104(2):251-9.

Hatzelmann A. J Pharmacol Exp Ther. 2001;297:267-79.

Iannuzzi MC, Rybicki BA, Teirstein AS. Sarcoidosis. N Engl J Med. 2007;357(21):2153-65.

Jain S, Williams DJ, Arnold SR, Ampofo K, Bramley AM, Reed C, ..., Zhu Y. Community-acquired pneumonia requiring hospitalization among US children. N Engl J Med. 2015;372(9): 835-45.

Jederlinic PJ, Sicilian L, Gaensler EA. Chronic eosinophilic pneumonia. A report of 19 cases and a review of the literature. Medicine (Baltimore). 1988;67:154.

Johansson SGO, et al. Revised nomenclature for allergy for global use: report of the Nomenclature Review Committee of the World Allergy Organization, October 2003. J Allergy Clin Immunol. 2006;117:367-77.

Johkoh T, Müller NL, Akira M, et al. Eosinophilic lung diseases: diagnostic accuracy of thin-section CT in 111 patients. Radiology. 2000;216:773.

Johnson S, Taveira D, Moss J. Lymphangioleiomyomatosis. Clin Chest Med. 2016;37:389-403.

Johnstone J, Majumdar SR, Fox JD, Marrie TJ. Viral infection in adults hospitalized with community-acquired 
pneumonia: prevalence, pathogens, and presentation. Chest J. 2008;134(6):1141-8.

Jorge S, Becquemin $\mathrm{MH}$, Delerme S, Bennaceur M, Isnard R, Achkar R, ..., Ray P. Cardiac asthma in elderly patients: incidence, clinical presentation and outcome. BMC Cardiovasc Disord. 2007;7(1): 16.

Judson MA, Boan AD, Lackland DT. The clinical course of sarcoidosis: presentation, diagnosis, and treatment in a large white and black cohort in the United States. Sarcoidosis Vasc Diffuse Lung Dis. 2012;29:119.

Kemp SF, et al. Anaphylaxis: a review of 266 cases. Arch Intern Med. 1995;155:1749-54.

King C, Moores L. Clinical asthma syndromes and important asthma mimics. Respir Care. 2008;53(5):568-82.

Kudo M, Ishigatsubo Y, Aoki I. Pathology of asthma. Front Microbiol. 2013;4:263.

Laidlaw TM, Boyce JA. Pathogenesis of aspirinexacerbated respiratory disease and reactions. Immunol Allergy Clin N Am. 2013;33(2):195.

Lamprecht P, Gross W. Wegener's granulomatosis. 2004. Retrieved from http:/www.ncbi.nlm.nih.gov/pubmed/ 14968341

Lecossier D, Valeyre D, Loiseau A, Cadranel J, Tazi A, Battesti JP, Hance AJ. Antigen-induced proliferative response of lavage and blood T lymphocytes. Comparison of cells from normal subjects and patients with sarcoidosis. Am Rev Respir Dis. 1991;144(4):861-8.

Li JT, Pearlman DS, Nicklas RA, et al. Algorithm for the diagnosis and management of asthma: a practice parameter update: Joint Task Force on Practice Parameters. Ann Allergy Asthma Immunol. 1998;81: 415-20.. (IIa)

Loffler W. Transient lung infiltrations with blood eosinophilia. Int Arch Allergy Appl Immunol. 1956;8:54.

Low K, Lau KK, Holmes P, Crossett M, Vallance N, Phyland D, ..., Bardin PG. Abnormal vocal cord function in difficult-to-treat asthma. Am J Respir Crit Care Med. 2011;184(1): 50-6.

Löwhagen O. Diagnosis of asthma - new theories. J Asthma. 2015;52(6):538-44.

Lund VJ. Bacterial sinusitis: etiology and surgical management. Pediatr Infect Dis J. 1994;13(1 Suppl 1): S58-63; discussion S63-5

Maillard I, Schweizer V, Broccard A, Duscher A, Liaudet L, Schaller MD. Use of botulinum toxin type A to avoid tracheal intubation or tracheostomy in severe paradoxical vocal cord movement. Chest J. 2000;118(3):874-7.

Marchand E, Reynaud-Gaubert M, Lauque D, et al. Idiopathic chronic eosinophilic pneumonia. A clinical and follow-up study of 62 cases. The grouped 'Etudeset de Recherchesur les Maladies “Orphelines” Pulmonaires (GERM“O”P). Medicine (Baltimore). 1998;77:299.

Marketos SG, Ballas CN. Bronchial asthma in the medical literature of Greek antiquity. J Asthma. 1982;19(4): 263-9.

Miller RD, Hyatt RE. Evaluation of obstructing lesions of the trachea and larynx by flow-volume loops 1-3. Am Rev Respir Dis. 1973;108(3):475-81.
Miravitlles M, et al. Respiration. 2000;67:495-501.

Moebus RG, Han JK. Immunomodulatory treatments for aspirin exacerbated respiratory disease. Am J Rhinol Allergy. 2012;26(2):134.

Montes de Oca M, et al. Eur Respir J. 2012;40:28-36.

Moorman JE, et al. National surveillance of asthma: United States, 2001-2010. National Center for Health Statistics. Vital Health Stat. 2012;3(35).

Morrison M, Rammage L, Emami AJ. The irritable larynx syndrome. J Voice. 1999;13(3):447-55.

Moss AJ, Parsons VL. Current estimates from the National Health Interview Survey. United States, 1985. Vital Health Stat. 1986;10:i-iv, 1-182

Musher DM, Thorner AR. Community-acquired pneumonia. N Engl J Med. 2014;371(17):1619-28.

National AE and Prevention P. Expert panel report 3 (EPR-3): guidelines for the diagnosis and management of asthma-summary report 2007. J Allergy Clin Immunol. 2007;120(5 Suppl):S94.

National Asthma Education and Prevention Program. 2007. Retrieved from https://www.nhlbi.nih.gov/files/ docs/guidelines/asthgdln.pdf

Nwokediuko SC. Current trends in the management of gastroesophageal reflux disease: a review. ISRN Gastroenterol. 2012;2012:391631.

Ohshimo S, Bonella F, Guzman J, Costabel U. Hypersensitivity pneumonitis. Immunol Allergy Clin $\mathrm{N}$ Am. 2012;32(4):537-56.

Pais F, Fayed M, Evans T. Lymphangioleiomyomatosis: an explosive presentation of a rare disease. Oxf Med Case Rep. 2017;2017(6):omx023.

Patterson R, et al. Idiopathic anaphylaxis. An attempt to estimate the incidence in the United States. Arch Intern Med. 1995;155:869-71.

Pongdee, T. Aspirin-exacerbated respiratory disease|AAAAI. n.d.. Retrieved 2 Sept 2017, from https://www.aaaai.org/ conditions-and-treatments/library/asthma-library/aspirinexacerbated-respiratory-disease

Ratner PH, Stoloff S, Meltzer EO, Hadley JA. Intranasal corticosteroids in the treatment of allergic rhinitis. Allergy Asthma Proc. 2007;28(Suppl 1):S 25-32.

Rich JD, Rich S. Clinical diagnosis of pulmonary hypertension. Circulation. 2014;130(20):1820-30.

Romanet-Manent S, et al. Allergic vs nonallergic asthma: what makes the differences? Allergy. 2002;57:607-13.

Saetta, et al. Am J Respir Crit Care Med. 1994;150: 1646-52.

Sakula A. Henry Hyde Salter (1823-71): a biographical sketch. Thorax. 1985;40(12):887-8.

Schrevens L, Vansteenkiste J, Deneffe G, De Leyn P, Verbeken E, Vandenberghe T, Demedts M. Clinicalradiological presentation and outcome of surgically treated pulmonary carcinoid tumours: a long-term single institution experience. Lung Cancer. 2004;43(1): 39-45.

Selman M, Buendía-Roldán I. Immunopathology, diagnosis, and management of hypersensitivity pneumonitis. In: Seminars in respiratory and critical care medicine 
(vol. 33, no. 05, pp. 543-554). Thieme Medical Publishers; 2012.

Sforza GGR, Marinou A. Hypersensitivity pneumonitis: a complex lung disease. Clin Mol Allergy. 2017;15(1):6.

Shamim S, Agarwal A, Ghosh BK, Mitra M. Fungal pneumonia in intensive care unit: when to suspect and decision to treatment: a critical review. J Assoc Chest Phys. 2015;3(2):41.

Sharma OP. Pulmonary sarcoidosis and corticosteroids. Am Rev Respir Dis. 1993;147:1598.

Simons FE, et al. World allergy organization guidelines for the assessment and management of anaphylaxis. World Allergy Organization. World Allergy Organ J. 2011; 4(2):13.. Epub 2011 Feb 23

Sontag SJ, Harding SM. Gastroesophageal reflux and asthma. 2006. Retrieved 24 Sept 2017.From http:// www.nature.com/gimo/contents/pt1/full/gimo47.html? foxtrotcallback $=$ true

Statement on sarcoidosis. Joint Statement of the American Thoracic Society (ATS), the European Respiratory Society (ERS) and the World Association of Sarcoidosis and Other Granulomatous Disorders (WASOG) adopted by the ATS Board of Directors and by the ERS Executive Committee, February 1999. Am J Respir Crit Care Med. 1999;160:736.

Stoller JK, et al. Cleve Clin J Med. 1994;61:461-7.

Taylor JR, Ryu J, Colby TV, Raffin TA. Lymphangioleiomyomatosis. N Engl J Med. 1990;323(18):1254-60.

Tazi A, Bouchonnet F, Valeyre D, Cadranel J, Battesti JP, Hance AJ. Characterization of gamma/delta T-lymphocytes in the peripheral blood of patients with active tuberculosis. A comparison with normal subjects and patients with sarcoidosis. Am Rev Respir Dis. 1992;146(5 Pt 1):1216-21.

Thomas KW, Hunninghake GW. Sarcoidosis. JAMA. 2003;289:3300.

Traister RS, Fajt ML, Landsittel D, Petrov AA. A novel scoring system to distinguish vocal cord dysfunction from asthma. J Allergy Clin Immunol Pract. 2014;2(1): 65-9.

Umeki S. Reevaluation of eosinophilic pneumonia and its diagnostic criteria. Arch Intern Med. 1992;152:1913.

Ungprasert P, Carmona EM, Utz JP, et al. Epidemiology of sarcoidosis 1946-2013: a population-based study. Mayo Clin Proc. 2016;91:183.

Ungprasert P, Crowson CS, Matteson EL. Influence of gender on epidemiology and clinical manifestations of sarcoidosis: a population-based retrospective cohort study 1976-2013. Lung. 2017a;195:87.
Ungprasert P, Crowson CS, Matteson EL. Epidemiology and clinical characteristics of sarcoidosis: an update from a population-based cohort study from Olmsted County, Minnesota. Reumatismo. 2017b;69(1):16-22.

Valent P, Klion AD, Horny HP, et al. Contemporary consensus proposal on criteria and classification of eosinophilic disorders and related syndromes. J Allergy Clin Immunol. 2012;130:607.

Wald ER, Applegate KE, Bordley C, Darrow DH, Glode MP, Marcy SM, Nelson CE, Rosenfeld RM, Shaikh N, Smith MJ, Williams PV, Weinberg ST. Clinical practice guideline for the diagnosis and management of acute bacterial sinusitis in children aged 1 to 18 years. Pediatrics. 2013;132(1):e262-80.

Walusiak J, Palczynski C. Carcinoid behind baker's asthma. Allergy. 2002;57(10):966-7.

Warrier P, et al. Omalizumab in idiopathic anaphylaxis. Ann Allergy Asthma Immunol. 2009;102:257-8.

Wijsenbeek MS, Culver DA. Treatment of sarcoidosis. Clin Chest Med. 2015;36:751.

Williams HL. The relationship of allergy to chronic sinusitis. Ann Allergy. 1966;24(10):521-34.

Wilson ME, Weller PF. Eosinophilia. In: Guerrant RL, Walker DH, Weller PF, editors. Tropical infectious diseases: principles, pathogens and practice. 2nd ed. Philadelphia: Elsevier; 2006. p. 1478.

Wong S, et al. Outcome of prophylactic therapy for idiopathic anaphylaxis. Ann Intern Med. 1991;114:133-6.

World Health Organization. The world health report 2003: shaping the future. Geneva: World Health Organization; 2003.

Wynn SR, O’Connell EJ, Frigas E, Payne WS, Sachs MI. Exercise-induced "asthma" as a presentation of bronchial carcinoid. Ann Allergy. 1986;57(2):139-41.

Yang IV, Lozupone CA, Schwartz DA. The environment, epigenome, and asthma. J Allergy Clin Immunol. 2017;140(1):14-23.

Yeh JJ, Wang YC, Hsu WH, Kao CH. Incident asthma and mycoplasma pneumoniae: a nationwide cohort study. J Allergy Clin Immunol. 2016;137(4):1017-23.

Zhou B, Guo Q, Zhou H, et al. Pulmonary lymphangioleiomyomatosis in a 46-year-old female: a case report and review of the literature. Biomed Rep. 2016;4(6): 719-22. https://doi.org/10.3892/br.2016.652.

Zimmerman B, Gold M. Role of sinusitis in asthma. Pediatrician. 1991;18(4):312-6.

Zuetenhorst JM, Taal BG. Metastatic carcinoid tumors: a clinical review. Oncologist. 2005;10(2):123-31. 